\title{
Multiobjective optimization of underground power cable systems
}

\author{
Paweł Ocłoń ${ }^{\text {a, }}$, Monika Rerak ${ }^{a}$, Ravipudi Venkata Rao ${ }^{b}$, Piotr Cisek ${ }^{a}$, Andrea Vallati ${ }^{c}$, \\ Dariusz Jakubek ${ }^{a}$, Bartosz Rozegnał ${ }^{\mathrm{d}}$ \\ a Cracow University of Technology, Department of Energy,al. Jana Pawła II 37, 31-864, Krakow, Poland \\ b Sardar Vallabhbhai National Institute of Technology Surat, Department of Mechanical Engineering, Surat, India \\ ${ }^{c}$ Department of Ingegneria Astronautica, Elettrica Ed Energetica, Sapienza University of Rome, Via Eudossiana 18, 00184, Rome, Italy \\ d Faculty of Electrical and Computer Engineering, Institute of Electromechanical Conversion, Cracow University of Technology, Warszawska 24 St., 31-155, \\ Cracow, Poland
}

\section{A R T I C L E I N F O}

\section{Article history:}

Received 14 February 2020

Received in revised form

11 October 2020

Accepted 12 October 2020

Available online 27 October 2020

\section{Keywords:}

High voltage underground power cable

system

Thermal backfill

Jaya algorithm

Finite element method

\begin{abstract}
A B S T R A C T
This paper presents a modified Jaya algorithm (MJaya) for optimizing the material costs and electricthermal performance of an Underground Power Cable System (UPCS). Three power cables arranged in flat formation are considered. Three XLPE high voltage cables are situated in the thermal backfill layer for ensuring the optimal thermal performance of the cable system. The cable backfill dimensions, cable backfill material, and cable conductor area are selected as design variables in the optimization problem. In the study, the Finite Element Method model is validated experimentally.

The Particle Swarm Optimization (PSO), Jaya, and MJaya algorithms are used for multiobjective optimization in order to design a cable system in such a way to minimize the cable backfill costs and maximize the allowable electric current flowing through the cables. For the case study, calculations performed using the Jaya algorithm indicated $1.7 \mathrm{mln}$ Euro cable system costs while cable ampacity is equal to $I=1460 \mathrm{~A}$. The calculations are performed for the objective function values equal to $w_{1}=0.5$ and $w_{2}=0.5$. Such an optimization parameters set allow obtaining low costs of UPCS alongside with reasonable cable line ampacity.

What is more, the results of the optimization obtained by Jaya, MJaya, and PSO algorithms are compared. Therefore, Coverage and Hypervolume metrics are incorporated. It is concluded that both the Jaya and MJaya algorithms performed better when compared to the PSO algorithm.
\end{abstract}

(c) 2020 Elsevier Ltd. All rights reserved.

\section{Introduction}

The Underground Power Cable Systems (UPCS) are recommended during the design and implementation in densely populated areas, electrical power outputs from power plants, and interconnections in power stations. However, the installation of underground power cables is still limited due to the high investment and maintenance costs as well as the expensive repairs in case of an outage. Report [1] shown that the UPCS could take from 48 to $480 \mathrm{~h}$ to get repaired during the outage, which is 6-10 times more than that of the overhead transmission lines. Furthermore, the power cables used underground still have higher prices than the overhead, because of the higher complexity in production [2].

The crucial factor that limits the power line ampacity is the

\footnotetext{
* Corresponding author.

E-mail address: pawel.oclon@pk.edu.pl (P. Ocłoń).
}

cross-sectional area of the power cable conductor. The conductor ampacity is defined as the maximum electrical current that may be carried safely by the wire without exceeding its insulation temperature limitations. Thus, the bigger the cable conductor crosssectional area is, the higher the current may be transferred safely under the given conditions. The cable conductor ampacity mostly depends on the cable core temperature. Therefore, the higher the electrical current is transmitted through the cable conductor, the higher the quantity of heat is generated in the form of Joule's heat within the cable core. The generated heat may cause an increase in the cable core temperature under unfavorable heat dissipation conditions. Thus, excessive conductor temperature, over $90{ }^{\circ} \mathrm{C}$ for XLPE-insulated power cables, leads to cable overheating and the improper operation of the power transmission line. An excessive cable core temperature, persisting for a long time, may result in the polyethylene insulation melting, which, in turn, causes the transmission line malfunction. Since the outage period may last even 


\begin{tabular}{|c|c|c|c|}
\hline \multicolumn{2}{|c|}{ Nomenclature } & $T$ & temperature, ${ }^{\circ} \mathrm{C}$ \\
\hline$A$ & cross-sectional area, $\mathrm{m}^{2}$ & $T_{c, \max }$ & maximum temperature of power cable operation, ${ }^{\circ} \mathrm{C}$ \\
\hline$b$ & $\begin{array}{l}\text { the distance between the conductors' axes and the } \\
\text { bottom of cable bedding layer, } m\end{array}$ & $\begin{array}{l}W \\
w_{1}, w_{2}\end{array}$ & $\begin{array}{l}\text { computational domain width, } \mathrm{m} \\
\text { weights of the functions } F_{1} \text { and } F_{2} \text {, respectively }\end{array}$ \\
\hline$C_{\text {backfill }}$ & Cable backfill costs, kEur/km & $\mathbf{X}$ & design variable vector, \\
\hline$C_{\text {backfill,u }}$ & backfill material unit costs, kEur $/ \mathrm{km}$ & $x, y$ & Cartesian coordinates, \\
\hline$C_{\text {cable }, u}$ & $\begin{array}{l}\text { pable costs, KEur } / \mathrm{km} \\
\text { power cable unit costs, kEur } / \mathrm{km}\end{array}$ & Subscripts & \\
\hline$C_{\text {total }}$ & $\begin{array}{l}\text { total material costs (cable plus thermal backfill } \\
\text { material costs) per km of cable line, kEuro/km }\end{array}$ & $\begin{array}{l}\text { backfill } \\
\text { best }\end{array}$ & $\begin{array}{l}\text { backfill } \\
\text { best solution in the population }\end{array}$ \\
\hline $\operatorname{Cov}(A, B)$ & $\begin{array}{l}\text { the coverage value of two non-dominated sets of } \\
\text { solutions (A and B) compared, }\end{array}$ & & $\begin{array}{l}\text { iteration number } \\
\text { design variable id }\end{array}$ \\
\hline$d$ & diameter, m & $k$ & $k$-th solution in population \\
\hline$F$ & objective (cost) function, & $m$ & number of design variables \\
\hline$F_{\text {scaled }}$ & objective function for the scaled approach, & $\min$ & minimum value of a parameter \\
\hline$F_{\text {clas }}$ & objective function for the classical approach & $\max$ & maximum value of a parameter \\
\hline$H$ & computational domain height, $\mathrm{m}$ & mean & mean value of parameter \\
\hline$h$ & burial depth, m & worst & the worst solution in the population \\
\hline$h_{\text {air }}$ & $\begin{array}{l}\text { heat transfer coefficient from the ground surface to } \\
\text { the ambient air, } \mathrm{W} /\left(\mathrm{m}^{2} \mathrm{~K}\right)\end{array}$ & Superscript & \\
\hline$I$ & current loading, A & ‘ & updated position of design variable vector $X$ \\
\hline$j$ & iteration number, & & \\
\hline$k$ & thermal conductivity, $\mathrm{W} /(\mathrm{m} \mathrm{K})$ & List of $A b b r$ & reviations \\
\hline$l$ & the spacing between two consecutive cables, m & FEM & Finite Element Method \\
\hline MAT & Material of thermal backfill & FTB & Fluidized Thermal Backfill \\
\hline$n$ & population size, & HDPE & High-density polyethylene \\
\hline$p$ & $\begin{array}{l}\text { the distance between the conductors' axes and the } \\
\text { top of cable bedding layer, } m\end{array}$ & $\begin{array}{l}\text { HV } \\
\text { HVol }\end{array}$ & $\begin{array}{l}\text { High Voltage } \\
\text { hypervolume }\end{array}$ \\
\hline$P F$ & penalty function, & PC & LaFarge POWERCRETETM \\
\hline$q_{v}$ & heat source density, $\mathrm{W} / \mathrm{m}^{2}$ & PSO & Particle Swarm Optimization \\
\hline$r_{1}, r_{2}$ & $\begin{array}{l}\text { random numbers generated during each iteration of } \\
\text { Jaya algorithm, }\end{array}$ & $\begin{array}{l}\text { SC } \\
\text { UPCS }\end{array}$ & $\begin{array}{l}\text { sand cement mix } \\
\text { underground power cable system }\end{array}$ \\
\hline$s$ & $\begin{array}{l}\text { spacing between the right edge of the bedding layer } \\
\text { and the side cable axis, } m\end{array}$ & XLPE & cross-linked polyethylene \\
\hline
\end{tabular}

$480 \mathrm{~h}$, and each hour entails huge financial losses related to the interruption of electricity transmission, the High Voltage (HV) underground transmission line failure rate must be reduced to a minimum [3].

To overcome the problem of cable overheating, the cable backfills are used, with higher thermal conductivity than the mother soil. Due to the low costs, approx. 40 euro per $\mathrm{m}^{3}$, the most commonly used thermal backfill is a sand-cement mixture with a proportion of $1-10$ or 1 to 12 . However, due to the relatively low thermal conductivity, reaching $0.8 \mathrm{~W} /(\mathrm{mK})$ ) in the dry state, this solution is not recommended in cases when the high carrying currents are needed. The other alternative could be Fluidized Thermal Backfill (FTB) with higher thermal conductivity, up to $1.54 \mathrm{~W} /(\mathrm{mK})$ in a dry state, and higher costs, approx. 125 euro per $\mathrm{m}^{3}$. Recently, the Heidelberg Cement Group proposed a new thermal backfill material, Cable Cem, with very high thermal conductivity, up to $2.5 \mathrm{~W} /(\mathrm{mK})$ in a dry state. This kind of solution, even though being expensive, may lead to reduce the cable core crosssectional area. It is very favorable and contributes to reducing the overall costs of the UPCS, allowing to achieve both lower temperature of power cables and lower total costs.

Many papers have been published so far on the optimization of the UPCS. Among the research carried out in this field, several articles related to the manuscript scope are mentioned. Andres [4] described two cases of the cable backfill design problem. At first, the minimization method of total backfill cost was described, when cable ampacity should not drop below the lower bound value. The costs considered producing the cable trench and laying the backfill material. What is more, the author described a procedure for cable line ampacity maximization while not exceeding the total cost budget.

Another interesting work was performed by Moutassem and Anders [5], who proposed a method for configuring the location of any number of underground cables to reach the highest total ampacity. Two-level optimization was adopted to find an optimal configuration. At first, the combinatorial optimization based on the Genetic Algorithm was used to find different possible configurations, which were then evaluated using an inner level optimization convex optimization algorithm. The convex optimization algorithm adopted the barrier method.

Ocłon et al. [6,7] proposed an algorithm for minimizing the cross-sectional area of thermal backfill for the UPCS. The $400 \mathrm{kV}$ power cable system laid in flat formation was considered. In Ref. [6], a new thermal backfill material was proposed based on the GruntarTm solution produced by the LaFarge company. The momentum-type Particle Swarm Optimization (PSO) was employed to find the thermal backfill layer cross-sectional area, which allows obtaining the cable core temperature lower than $65{ }^{\circ} \mathrm{C}$. The Cambel - de Vries model, was used to determine the soil thermal conductivity.

Quan et al. [8] studied the thermal performance of UPCS in trefoil and flat formation using Fluidized Thermal Backfill as cable 
bedding material, while Klimenta et al. [9] considered the use of Hydronic Asphalt Pavement (HAP) within the system. The use of HAP is proposed for eliminating the negative thermal effect of an actual hot spot on the ampacity of a $110 \mathrm{kV}$ cable line, which is installed in parallel with the group of four $35 \mathrm{kV}$ cables and which crosses an underground heating pipeline. In another manuscript, Klimenta et al. [10] studied the thermal effect of solar radiation on the ampacity of a low voltage underground cable.

Economical analysis of cable line design was performed in the papers of Cichy et al. [11,12]. In the abovementioned research, Cichy et al. [11] extended the models for economic conductor sizing discussed in the literature by presenting a detailed cost analysis of the cable itself. The authors found that the classical linear model is valid, and the proposed approach permits the quite precise computation of its parameters. What is more, in Ref. [12], Cichy et al. presented a mathematical model for the selection of an optimal power cable conductor cross-section and the dimensions of a corrective backfill. The model considered the material and labor costs in the production of a power cable as well as the cost of losses during its operation. A genetic algorithm was used in the optimization procedure.

Zachri et al. [13] developed a method to find the optimal configuration of the cables in a duct bank considering the current harmonics and their effect on sheath losses. Two optimization algorithms, PSO and Shuffled Frog Leaping algorithms, were used. In the next paper, Zarchi and Vahidi [14] proposed an algorithm for calculating the optimal configuration set of underground cables in the concrete duct bank, simultaneously maximizing the ampacity and minimizing the cost of system. A Particle Swarm Optimization was employed.

Summing up state of the art, in Table 1, a brief synthesis of the analyzed papers are presented. (see Table 2).

In the developed numerical models of heat transfer in the cable line systems, the parameters of the soil and the cable backfill, in which the power cables are located, are very important. Thus, extensive research is carried out in order to determine the thermal properties of soil and backfill in the vicinity of the cable line. The research of Kroener et al. [15] and Hruška et al. [16] confirms that the heat generated in power cables affects soil water content considerably, which in turn has a significant impact on soil thermal conductivity. Being aware of these interdependencies, the authors have studied the effect of soil and thermal backfill conductivity on the temperature distribution in the UPCS in the papers $[17,18]$.

The scope of this paper is to present the procedure for
Table 2

Design variables and their change ranges considered in the computation.

\begin{tabular}{ll}
\hline Variable, unit & Change range \\
\hline$l, \mathrm{~m}$ & $0.3<l<0.6$ \\
$p, \mathrm{~m}$ & $0.2<p<0.4$ \\
$b, \mathrm{~m}$ & $0.2<b<0.4$ \\
$S, \mathrm{~m}$ & $0.2<s<0.4$ \\
$A_{c}, 10^{-6} \mathrm{~m}^{2}$ & $1000,1200,1400,1600,1800,2000$ \\
$I, \mathrm{~A}$ & $1200<I<1600$ \\
$M A T$ & SC, FTB, CC \\
\hline
\end{tabular}

multiobjective optimization of UPCS design on an example of a flatformation $400 \mathrm{kV}$ underground transmission line. The present paper is a continuation of the previous work reported in Ref. [3], where the single-objective optimization of underground power cable costs was proposed by using a modified Jaya algorithm. However, from the cable line operation standpoint, it is needed to optimize both the material costs and cable ampacity. Therefore, in this paper, multiobjective optimization is performed to improve the design of the UPCS. The proposed procedure allows us to reduce the UPCS costs, as well as to maintain the electrical current carried by the cables at an acceptable level. The objective function, including both material costs of the UPCS and electrical current flowing through the cable, is defined for the optimization problem to be solved. The modified Jaya (MJaya) algorithm is proposed as the optimization tool that is able to minimize the objective function. The performance of the modified Jaya algorithm is compared with the classical Jaya algorithm and PSO.

\section{Analysis and modelling}

As a test case, the HV underground transmission line of three $400 \mathrm{kV}$ XLPE-insulated power cables, arranged in flat formation (Fig. 1) is concerned. The power cables are buried underground in the rectangular trench filled with the thermal backfill layer. The backfill is situated in soil with constant thermal conductivity.

The primary goal of the optimization is to satisfy the following requirements:

a) minimization of the unitary material costs (costs of cables and thermal backfill applied per $1 \mathrm{~km}$ of the transmission line),

b) maximizing the current $I$ transferred through the cable,

Table 1

Summary of th literature references regarding UPCS optimization methods employed.

\begin{tabular}{|c|c|c|}
\hline Study & Optimization algorithm employed & Results of the analysis \\
\hline Andres [4] & & $\begin{array}{l}\text { o minimization method of total backfill cost while cable ampacity should not drop } \\
\text { below the lower bound value; } \\
\text { o procedure for cable line ampacity maximization while not exceeding the total cost } \\
\text { budget; }\end{array}$ \\
\hline $\begin{array}{l}\text { Moutassem } \\
\text { and Anders } \\
\text { [5] }\end{array}$ & $\begin{array}{l}\text { two-level optimization algorithm: } \\
\text { o at the outer level, the Vector Immune System algorithm explores } \\
\text { the different possible configurationsm } \\
\text { o at the inner level, a convex optimization algorithm based on the } \\
\text { barrier method to evaluate total ampacity of the system }\end{array}$ & $\begin{array}{l}\text { configuring the location of any number of underground cables to reach the highest } \\
\text { total ampacity. }\end{array}$ \\
\hline $\begin{array}{l}\text { Ocłoń et al. } \\
{[6,7]}\end{array}$ & momentum-type Particle Swarm Optimization & $\begin{array}{l}\text { finding the thermal backfill layer cross-sectional area, which allows obtaining the } \\
\text { cable core temperature lower than } 65^{\circ} \mathrm{C}\end{array}$ \\
\hline $\begin{array}{l}\text { Cichy et al. } \\
\text { [12] }\end{array}$ & Genetic Algorithm & $\begin{array}{l}\text { selection of an optimal power cable conductor cross-section and the dimensions of a } \\
\text { cable backfill taking into account the material and labor costs in the production of a } \\
\text { power cable as well as the cost of losses during its operation. }\end{array}$ \\
\hline $\begin{array}{l}\text { Zachri et al. } \\
\text { [13] }\end{array}$ & PSO and Shuffled Frog Leaping algorithm & $\begin{array}{l}\text { optimal configuration of the cables in a duct bank considering the current harmonics } \\
\text { and their effect on sheath losses }\end{array}$ \\
\hline $\begin{array}{l}\text { Zarchi and } \\
\text { Vahidi [14] }\end{array}$ & PSO algorithm & $\begin{array}{l}\text { calculating the optimal configuration set of underground cables in the concrete duct } \\
\text { bank, simultaneously maximizing the ampacity and minimizing the cost of the system }\end{array}$ \\
\hline
\end{tabular}


(a)

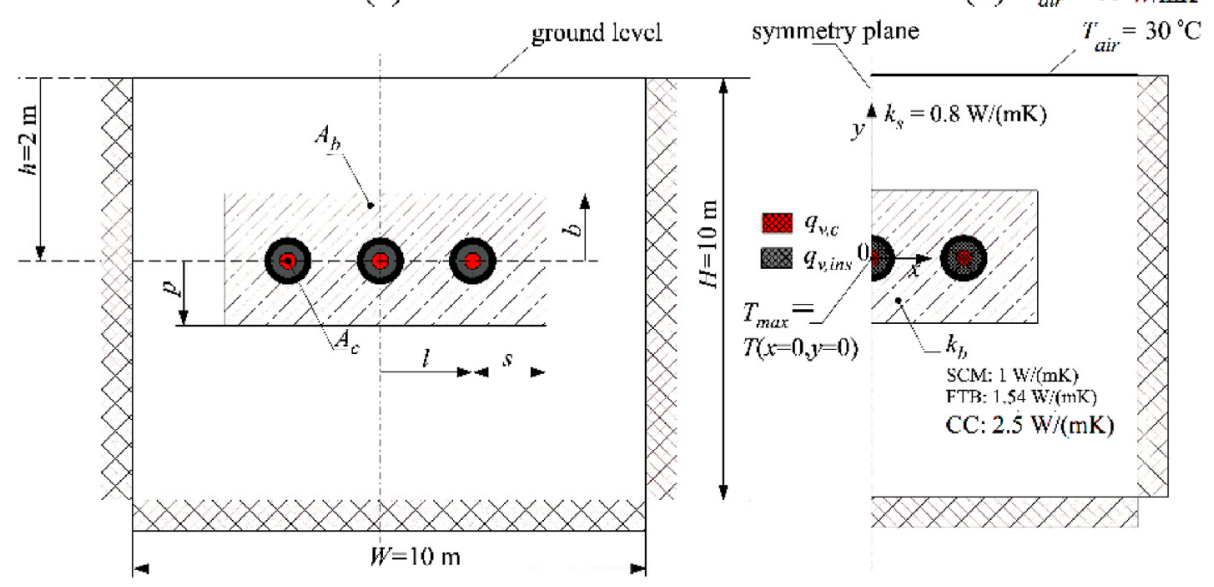

(c)
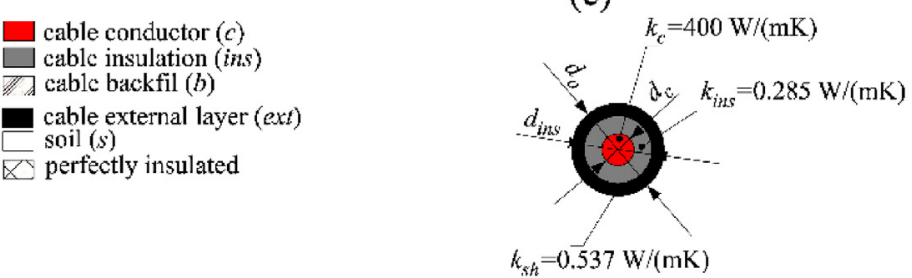

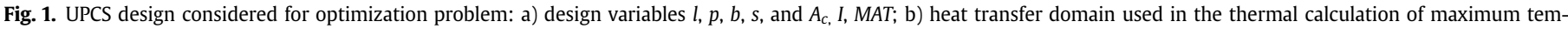

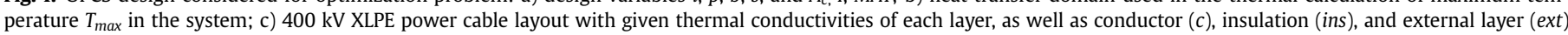
diameters.

c) the maximum temperature of the cable conductor shall not exceed the maximum temperature of power cable operation, i.e., $T_{c, \max }=90^{\circ} \mathrm{C}$.

In order to simulate the adverse heat transfer conditions that occur in the soil during the summertime, the temperature of the ground level is set and equal to $30{ }^{\circ} \mathrm{C}$, while the convective heat transfer coefficient is considered to be equal to $10 \mathrm{~W} /\left(\mathrm{m}^{2} \mathrm{~K}\right)$.

\subsection{Design variables and constraints}

The following design variables are used in the optimization problem (concerning Fig. 1):

$l$ - horizontal distance between the cable conductors axes,

$s$ - spacing between the right edge of the bedding layer and the side cable axis,

$b$ - the distance between the conductor axes and the top of the bedding layer,

$p$ - the distance between the conductor axes and the bottom of the bedding layer.

$A_{c}$ - nominal cable conductor cross-sectional area (selected from the XLPE HV cable design series, provided by the cable producer).

$I$ - electric current flowing through the cable.

MAT - Material of thermal backfill (sand cement mix - SC, Fluidized Thermal Backfill - FTB, Cable Cem - CC).

The dimensions of the computation domain are: domain width $W=5 \mathrm{~m}$, domain height $H=10 \mathrm{~m}$, and burial depth $h=2 \mathrm{~m}$. The following ranges of design variables are considered:

Seven design variables are considered including the dimensions of thermal backfill $(l, p, b, s)$, power cable cross-sectional area $A_{c}$, electric current transferred $I$, and thermal backfill material MAT (Sand cement mixture, Fluidized Thermal Backfill or Cable Cem).

The unit costs of underground power cables considered are given in Tables 3 and 4.

The total material costs for the HV cable line installation are calculated as follows:

$C_{\text {total }}=C_{\text {cable }}+C_{\text {backfill }}$

where the cost of power cables $C_{\text {cable }}$ is:

$C_{\text {cable }}=3 C_{\text {cable }, u}$,

while the cost of thermal backfill is calculated as:

$C_{\text {backfill }}=1000 \cdot A_{\text {backfill }} C_{\text {backfill }, u}$

The cross-sectional area of the thermal backfill layer is calculated as:

$A_{\text {backfill }}=2(l+s)(p+b)-3 \pi \frac{d_{0}^{2}}{4}$

where $d_{o}$ is the outer diameter of power cable and may be calculated from the following equation, based on the data from Ref. [22]:

$d_{0}=-1.210^{9} A_{c}^{4}+1.5 \cdot 10^{7} A_{c}^{3}-5.4 \cdot 10^{4} A_{c}^{2}+96 A_{c}+0.063$

Table 3

Unit costs of the power cables corresponding to the cross-sectional area $\left(A_{c}\right)$.

\begin{tabular}{ll}
\hline Cable cross-sectional area $A_{c}, 10^{-6} \mathrm{~m}^{2}$ & Cable unit costs $C_{\text {cable,u }}, \mathrm{kEuro} / \mathrm{km}$ \\
\hline 1000 & 268.8 \\
1200 & 320.4 \\
1400 & 373.6 \\
1600 & 446.0 \\
1800 & 526.3 \\
2000 & 626.0 \\
\hline
\end{tabular}


Table 4

Unit costs of power backfill materials assumed in the computation.

\begin{tabular}{ll}
\hline MAT & Backfill material unit costs ${ }^{\mathrm{a}} C_{\text {backfill, }}$ Euro $/ \mathrm{m}^{3}$ \\
\hline Sand Cement Mix & 40 \\
Fluidized Thermal Backfill (FTB) & 125 \\
Cable Cem & 250 \\
\hline
\end{tabular}

a The backfill material costs may differ from the actual values.

The optimization includes both the scaled and classical approach in minimizing the final objective function. Taking into account that:

$F_{1}=10^{-3} C_{\text {total }}$

and

$F_{2}=10^{-3} I$,

the minimization of the following objective function is considered for the:

- scaled approach

$F_{o b j}=w_{1}\left(\left(F_{1}-F_{1, \min }\right) /\left(F_{1, \max }-F_{1, \min }\right)\right)+$

$+w_{2}\left(\left(F_{2, \max }-F_{2}\right) /\left(F_{2, \max }-F_{2, \min }\right)\right)+P F$,

In Eq (8) $w_{1}$ and $w_{2}$ are the weights of the functions $F_{1}$ and $F_{2}$, respectively. The values of $F_{1, \max }$ and $F_{1, \min }$ as well as the values of $F_{2, \max }$ and $F_{2, \min }$ are obtained by carrying out the single-objective optimization of the respective individual objective functions and are listed in Table 5.

Objective function $F_{1}$ should be minimized, while objective function $F_{2}$ should be maximized. To define the global optimization problem and minimize the objective function $F_{o b j}$ we need to reformulate the optimization problem and minimize the weighted sum of the $F_{1}$ and $F_{2}$ related functionals. In a scaled approach, the higher the value of $F_{2}$, the lower the value of

$w_{2}\left(\left(F_{2, \max }-F_{2}\right) /\left(F_{2, \max }-F_{2, \min }\right)\right)$

When $F_{2}$ approaches $F_{2 \text {,max }}$, then the functional value tends to 0 . Also, the lower value of $F_{1}$, the lower value of weighted functional:

$w_{1}\left(\left(F_{1}-F_{1, \min }\right) /\left(F_{1, \max }-F_{1, \text { min }}\right)\right)$

When $F_{1}$ approaches $F_{1, \min }$, then the functional value tends to 0 . Therefore, with minimizing $F_{1}$ and maximizing $F_{2}$ the objective function $F_{o b j}$ is minimized.

$P F$ in Eq. (8) is a penalty function given by the following relationship:

$P F=10\left(T_{\max }-90^{\circ} \mathrm{C}\right)$

The penalty function $P F$ is equal to 0 if the $T_{\max }$ temperature is lower than $90^{\circ} \mathrm{C}$ and higher than 0 otherwise.

For safe operation of the UPCS, it is needed to minimize the

Table 5

The values of $F_{1, \max }$ and $F_{1, \min }$ and $F_{2, \max }$ and $F_{2, \text { min }}$ considered in the computation.

\begin{tabular}{ll}
\hline Objective function & Value \\
\hline$F_{1, \min }$ & 1.2873 \\
$F_{1, \max }$ & 2.2666 \\
$F_{2, \min }$ & 1.20 \\
$F_{2, \max }$ & 1.60 \\
\hline
\end{tabular}

thermal backfill costs while operating at the highest possible ampacity (current carrying capacity). Therefore, the multiobjective optimization aims to minimize the costs of the system while maximizing the current. Since there are contrasting two objective functions for minimizing the system costs and maximizing current, it is needed to perform multiobjective optimization. Therefore, the present paper is minimizing $F_{1}$ and maximizing $F_{2}$ under different weights.

\subsection{Electric-thermal model of the UPCS}

The scheme of the heat transfer domain is shown in Fig. 1. The following assumptions are made when modeling the temperature field in the UPCS:

- heat transfer is considered as two-dimensional and steadystate,

- heat losses in cable conductor and the cable insulation layer are considered,

- the sides of the heat transfer domain are considered to be perfectly insulated,

- the thermal conductivity of soil, thermal backfill material, and cable-layers are assumed to be constant.

When determining the maximum temperature of the central cable conductor $T_{\max }$, a two-dimensional heat conduction equation is solved using the Finite Element Method (FEM) code developed for this purpose [3].

- for the cable conductor:

$\frac{\partial}{\partial x}\left[k_{c} \frac{\partial T(x, y)}{\partial x}\right]+\frac{\partial}{\partial y}\left[k_{c} \frac{\partial T(x, y)}{\partial y}\right]=-q_{v, c}(T(x, y))$,

- for the XLPE insulation:

$\frac{\partial}{\partial x}\left[k_{i n s} \frac{\partial T(x, y)}{\partial x}\right]+\frac{\partial}{\partial y}\left[k_{i n s} \frac{\partial T(x, y)}{\partial y}\right]=-q_{v, i n s}(T(x, y))$,

- for cable external layer:

$\frac{\partial}{\partial x}\left[k_{\text {ext }} \frac{\partial T(x, y)}{\partial x}\right]+\frac{\partial}{\partial y}\left[k_{\text {ext }} \frac{\partial T(x, y)}{\partial y}\right]=0$,

- for the soil

$\frac{\partial}{\partial x}\left[k_{s} \frac{\partial T(x, y)}{\partial x}\right]+\frac{\partial}{\partial y}\left[k_{s} \frac{\partial T(x, y)}{\partial y}\right]=0$,

- for the cable backfill

$\frac{\partial}{\partial x}\left[k_{b} \frac{\partial T(x, y)}{\partial x}\right]+\frac{\partial}{\partial y}\left[k_{b} \frac{\partial T(x, y)}{\partial y}\right]=0$,

where:

$x, y$ - are the Cartesian coordinates of the specified point that belongs to the heat transfer domain, $q_{v}(T(x, y))$ - is a heat source density, $\mathrm{W} / \mathrm{m}^{2}$.

$k-$ is thermal conductivity specified for the different computational domains, i.e.:

- for the cable conductor, $k_{c}=400 \mathrm{~W} /(\mathrm{m} \mathrm{K})$,

- for the cable XLPE insulation, $k_{\text {ins }}=0.285 \mathrm{~W} /(\mathrm{m} \mathrm{K})$,

- for the cable external layer, $k_{\text {ext }}=0.534 \mathrm{~W} /(\mathrm{m} \mathrm{K})$,

- for the soil, $k_{s}=0.8 \mathrm{~W} /(\mathrm{m} \mathrm{K})$,

- for different types of thermal backfill, i.e.

- for the Sand-Cement mix, $k_{b}=0.8 \mathrm{~W} /(\mathrm{m} \mathrm{K})$,

- for FTB, $k_{b}=1.54 \mathrm{~W} /(\mathrm{m} \mathrm{K})$,

- for Cable Cem ${ }^{\mathrm{TM}}, k_{b}=2.5 \mathrm{~W} /(\mathrm{m} \mathrm{K})$. 
The system of equations given in Eq. (11) is subjected to the following boundary conditions:

$\left.k \frac{\partial T}{\partial x}\right|_{x=W}=0$

$\left.k \frac{\partial T}{\partial x}\right|_{x=0}=0$,

$\left.k \frac{\partial T}{\partial y}\right|_{y=h-H}=0$

$\left.k \frac{\partial T}{\partial x}\right|_{y=h}=h_{\text {air }}\left(T(y)-T_{\text {air }}\right)$

where $h_{\text {air }}=10 \mathrm{~W} /\left(\mathrm{m}^{2} \mathrm{~K}\right)$ is the heat transfer coefficient from the ambient air to the ground, and $T_{\text {air }}=30{ }^{\circ} \mathrm{C}$ is the external air temperature. The methodology of heat loss calculation in cable conductor $q_{v, c}(T(x, y))$, and cable insulation $q_{v, \text { ins }}(T(x, y))$ is described in detail in Refs. [3].

The cable layouts are adopted into FEM model by using data from the Nexans High Voltage Underground Power Cables catalog. Equation (13) provides the formula for heat losses in cable core $[4,21]$.

$q_{v, c}(T(x, y))=\frac{\Delta Q_{c}}{A_{c, c a l}}$

where

$\Delta Q_{c}=\frac{I^{2} \rho_{20} C}{A_{c, c a l}}\left[1+\alpha_{r e f}\left(T_{c}(x, y)-T_{r e f}\right)\right]\left(1+y_{s}+y_{p}\right)$

and.

$\rho_{20}=1.724110^{-8} \Omega \mathrm{m}-$ copper electrical resistance.

$C=1.02 \mathrm{~m}-$ sample length.

$T_{\text {ref }}=20^{\circ} \mathrm{C}$ - reference temperature.

$T_{C}$ - the average cable conductor temperature ${ }^{\circ} \mathrm{C}$,

$\alpha_{\text {ref }}=0.00393$-copper conductor temperature coefficient.

$\Delta Q_{c}$-cable conductor heat loss, $\mathrm{W} / \mathrm{m}$,

$d_{c}$ - power cable core equivalent diameter for $400 \mathrm{kV}$ power cables, $\mathrm{m}$,

$y_{s}$ and $y_{p}-$ skin and proximity effect factors.

XLPE HV power cable equivalent cross-sectional area $A_{c, \text { cal }}$ is given by:

$A_{c, c a l}=\left(\sum_{i-0}^{3} p_{i, c} A_{c}^{i}\right)$

with $p_{0, i}$ to $p_{3, i}$ coefficients equal to $p_{0, i}=0.0007955, p_{1, i}=0.3697$, $p_{2, i}=-76.04, p_{3, i}=1.673 \cdot 10^{5}$.

The skin and proximity factors, $y_{s}$ and $y_{p}$, are obtained based on IEC 60287, 2014, standard.

When defining $x_{s}$ the following formula is used:

$x_{s}=\frac{8 \pi f}{R^{\prime}} \cdot 10^{-7} K_{s}$,

where

$R^{\prime}=\frac{I^{2} \rho_{20} C}{A_{c, \text { cal }}}\left[1+\alpha_{\text {ref }}\left(T_{C}(x, y)-T_{r e f}\right)\right]$

skin effect factor $y_{s}$ is calculated as follows: $y_{s}=\frac{x_{s}^{4}}{192+0.8 x_{s}^{4}}$, for $0<x_{s} \leq 2.8$

$y_{s}=-0.136-0.0177 x_{s}+0.0563 x_{s}^{2}$, for $2.8<x_{s} \leq 3.8$,

and

$y_{s}=0.354 x_{s}-0.733$, for $x_{s}>3.8$

For a given value of $x_{p}$ :

$x_{p}=\frac{8 \pi f}{R^{\prime}} \cdot 10^{-7} K_{p}$

the proximity effect factor $y_{p}$ is calculated as:

$y_{p}=\frac{x_{p}^{2}}{192.0 .8 x_{p}^{2}}\left(\frac{d_{c}}{l}\right)^{2}\left[0.312\left(\frac{d_{c}}{l}\right)^{2}+\frac{1.18}{\frac{x_{p}^{2}}{192+0.8 x_{p}^{2}}+0.27}\right]$

In Eqs (16) - (22), $l$ is a distance between cables, and $f$ is an alternating current frequency, equal to $50 \mathrm{~Hz}$. The values of $K_{s}$ and $K_{p}$, are equal to 0.37 and 0.8 , respectively, according to ICE 60287 , 2014. The Round Milliken bare bi-directional wires are considered.

The value of $q_{v, \text { ins }}$, referred to the insulation cross-section area $A_{\text {ins,cal }}$, is determined by:

$q_{v, \text { ins }}=\frac{\Delta Q_{\text {ins }}}{A_{\text {ins }, \text { cal }}}$

where

$\Delta Q_{i n s}=2 \pi f C_{i n s} \frac{U^{2}}{3} \tan \delta$

when the given parameters are:

$C_{i n s}$ - capacitance calculated according to Nexans, 2011, F/m,

$\tan \delta$ - insulation loss factor equal to $\tan \delta=0.005$.

$U$ - the maximum AC voltage, $\mathrm{V}$.

The value of $A_{\text {ins,cal }}$ is determined as:

$A_{\text {ins }, \mathrm{cal}}=\left(\sum_{i=0}^{3} p_{i, i n s} A_{c}^{l}\right)$,

with $p_{0, \text { ins }}$ to $p_{3, \text { ins }}$ coefficients equal to: $p_{0, i n s}=0.002695$, $p_{1, \text { ins }}=4.725, p_{2, \text { ins }}=-1590, p_{3, \text { ins }}=2.72 \cdot 10^{5}$.

\subsection{Optimization algorithms used}

This paper compares the performance of the Jaya algorithm, Modified Jaya (MJaya) algorithm, and PSO.

\subsubsection{Jaya algorithm}

The flowchart of the Jaya algorithm is presented in Fig. 2. In the optimization problem we consider the design variables vector $x=\left[l, p, b, s, A_{c}, I, M A T\right]$ and for an $i$-th generation with $n$ elements we denote a design variables vector set as $X_{j, k, i}=\left[x_{j, 1, i}, x_{j, 2, i}, x_{j, 3, i}, x_{j, 4, i}\right.$, $\left.\ldots, x_{j, n, i}\right]^{T}$.

The equation which is used in the Jaya algorithm to update the candidate position during the $i$-th iteration is: 


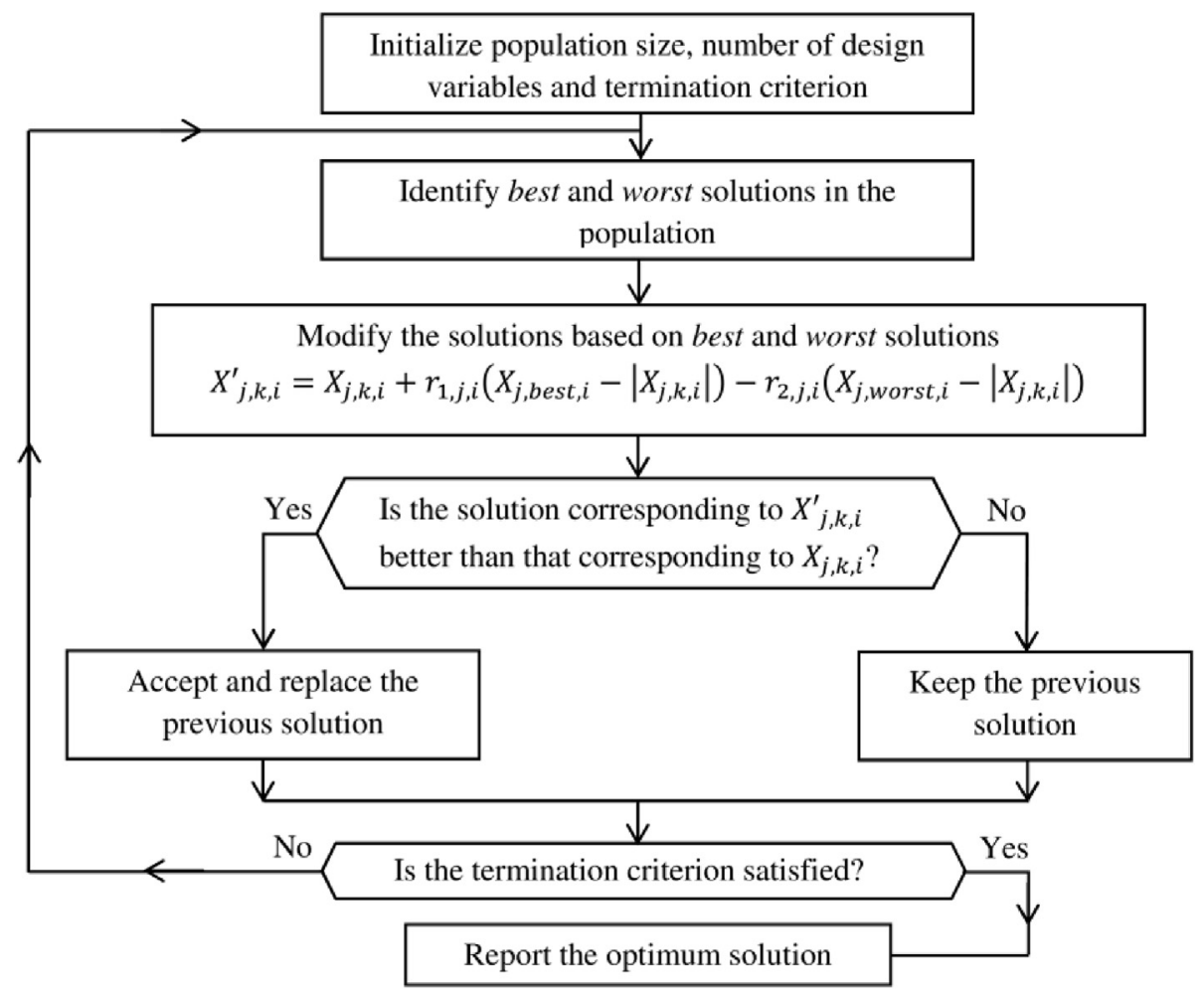

Fig. 2. Flowchart of the modified Jaya algorithm [19].

$X_{j, k, i}^{\prime}=X_{j, k, i}+r_{1, j, i}\left(X_{j, b e s t, i}-\left|X_{j, k, i}\right|\right)-r_{2, j, i}\left(X_{j, w o r s t, i}-\left|X_{j, k, i}\right|\right)$,

where, $X_{j, b e s t, i}$ is the value of the variable $j$ for the best candidate and $X_{j, \text { worst }, i}$ is the value of the variable $j$ for the worst candidate. $X_{j, k, i}^{\prime}$ is the updated value of $X_{j, k, i}$, while $r_{1, j, i}$, and $r_{2, j, i}$ are the two random numbers for the $j$ th variable during the $i$ th iteration in the range $[0,1]$.

\subsubsection{Modified Jaya algorithm (MJaya)}

The modified version of the Jaya (MJaya) algorithm considers the changes in Eq. (26) as follows:

$X_{j, k, i}^{\prime}=X_{j, k, i}+r_{1, j, i}\left(X_{j, b e s t}(r b), i-\left|X_{j, k, i}\right|\right)-r_{2, j, i}\left(X_{j, \text { worst }, i}-\left|X_{j, k, i}\right|\right)$,

where, $r b$ is a random integer 1,2 or 3, and best (1), best (2) and best (3) are solution candidates with the first best (1), the second-best (2) and the third-best (3) values of the objective function within the population during an iteration. The solution candidate position is updated as per Eq. (27). One of the three best values will be randomly selected during the iteration.

\subsubsection{PSO algorithm}

The PSO algorithm calculates the velocity of each particle as follows:

$V_{j, k, i}^{\prime}=w V_{j, k, i}+c_{1} r_{1, j, i}\left(X_{j, p b e s t, i}-X_{j, k, i}\right)+c_{2} r_{2, j, i}\left(X_{j, g b e s t, i}-X_{j, k, i}\right)$,

where $w$ is the inertia weight equal to: $w=w_{\max }-\frac{i\left(w_{\max }-w_{\min }\right)}{i_{\max }}$

while $i$ denotes the iteration number, $i_{\max }$ is the maximum number of iterations, $w_{\max }=0.9$, and $w_{\min }=0.4$. The symbols $c_{1}$ and $c_{2}$ in Eq. (15) are acceleration coefficients. Then $c_{1}$ value indicates the importance of personal best value (pbest) and $c_{2}$ value indicates the importance of the global best (gbest) value of the solution candidate. The candidate position is updated in the consecutive iteration as follows:

$X_{j, k, i}^{\prime}=X_{j, k, i}+V_{j, k, i}^{\prime}$

The multiobjective optimization problem, given by Eq. (8) - a scaled approach, is solved by using the Jaya, modified Jaya, and PSO algorithms. The results of these three algorithms are compared and discussed. Table 6 presents the advantages and disadvantages of PSO, JAYA and MJAYA.

\section{Model validation}

Fig. 3 presents a scheme of the experimental setup used for FEM model validation. The setup consists of three resistance heaters arranged inline. The heaters are placed in HDPE pipes with an external diameter of $60 \mathrm{~mm}$, and a thickness of $2 \mathrm{~mm}$, then filled with glass granulate. The box is filled with sand, and the box dimensions are the height of $1000 \mathrm{~mm}$, and the width of $1300 \mathrm{~mm}$. The sides of the box are insulated with extruded styrofoam to reduce the heat losses to the surroundings. The top and bottom of the domain are not insulated. Therefore the convective heat transfer occurs. Three cylindrical resistance heaters with a diameter of $11.3 \mathrm{~mm}$ and a length of $1 \mathrm{~m}$ are buried in a box at a depth of $500 \mathrm{~mm}$.

Temperature distribution in the sand domain is measured in 25 
Table 6

Advantages and disadvantages of PSO, JAYA and MJAYA

\section{Particle Swarm Optimization (PSO)}

\section{Advantages}

1. The operation of the algorithm is not sensitive to the type of objective function (multidimensional, irregular, discontinuous or even non-parametric).

2. The efficiency of the algorithm is independent of the initial values. The final solution does not depend on a set of initial points or initial population.

3. It is a method that does not use derivative of objective function.

4. High performance and searchability of the space solution as the solution is updated based on the best global solution and the best solution for a given particle.

5. It is simple in programming since only one evolutionary equation is used

\section{Disadvantages}

1. There is no guarantee that after each iteration only improved solutions are generated

2. Requires tuning of algorithm-specific parameters such as inertia weight and cognitive and social coefficients.

3. Entrapment into local optima.

4. Importance is given only to the best solution therefore the algorithm may show poor ability to recover from the local optima.

5. It is required to maintain a database of local best and global best solutions.

\section{JAYA}

\section{Advantages}

1. The working of the algorithm is not sensitive to the nature of the objective function

2. The performance of the algorithm is independent of initial solutions.

3. It is a derivative free technique.

4. A solution is updated based on population best and population worst. This gives a good exploration and exploitation capability to the algorithm.

5. Does not involve tuning of any algorithm-specific parameters like PSO.

6. Solutions are updated in a single equation.

\begin{tabular}{|c|}
\hline Disadvantages \\
\hline $\begin{array}{l}\text { 1. Only good solutions are allowed to go into the next phase, thereby elitism is not preserved. } \\
\text { 2. As the solutions reach closer to the global optima the difference between best and the worst solution reduces. Therefore, the exploration reduces slightly due to lack of } \\
\text { gradient information. }\end{array}$ \\
\hline MJAYA \\
\hline Advantages \\
\hline $\begin{array}{l}\text { 1. Can be applied to all kind of objective function types } \\
\text { 2. Has all the advantages of JAYA algorithm i.e. the performance is independent on initial solution, derivative free technique, no need of algorithm specific parameters } \\
\text { tuning, only good solutions remains in the next generation. } \\
\text { 3. A solution is updated based on population three best and population worst solutions. This gives an enhanced exploration and exploitation capability to the algorithm } \\
\text { compared to JAYA. }\end{array}$ \\
\hline Disadvantages \\
\hline
\end{tabular}

points shown in detail in Fig. 3a. The K-type thermocouples are used for temperature measurements. The thermocouples are located at the steel rods placed in the box, to achieve accurate positioning during the measurements. The measurement accuracy is $\pm 0.2{ }^{\circ} \mathrm{C}$. During the temperature sensors installation, the tips of the thermocouples might be dislocated slightly. Therefore, the

(a)

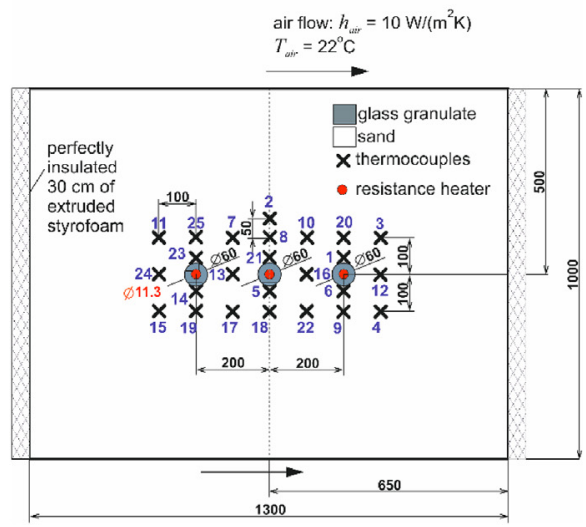

thermocouples positioning uncertainty is estimated at $\pm 1 \mathrm{~mm}$. During the experimental investigation, the electrical current of $I=1.54 \mathrm{~A}$, and voltage of $U=228 \mathrm{~V}$ was achieved, so the power output for a single heater is of $P=34.1 / 3=11.36 \mathrm{~W}$. Fig. 3b shows the test stand assembled.

Sand thermal conductivity was measured using the KD2 Pro (a)

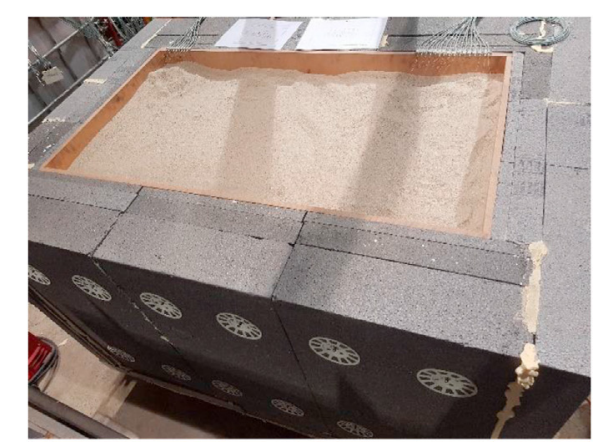

Fig. 3. Experimental setup for measurements of temperature distribution within the UPCS: a) location of the temperature sensors; b) photograph of the test stand. 


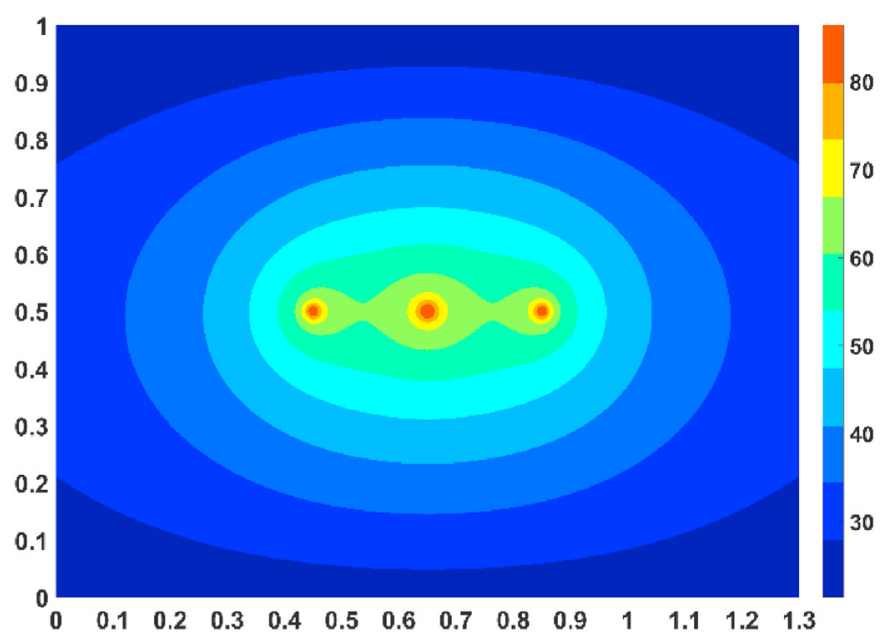

Fig. 4. Calculated temperature distribution in the UPCS.

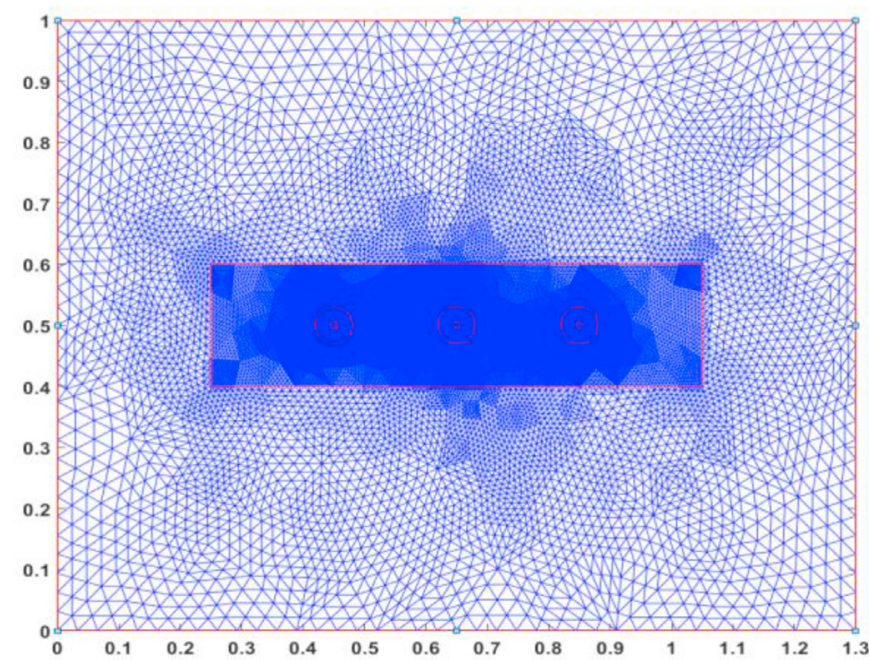

Fig. 5. Numerical grid used in the computations.

device delivered by Decagon Devices and is equal to $k_{s}=0.6 \mathrm{~W} /$ $(\mathrm{mK})$. The heater material (steel) thermal conductivity is assumed as $60 \mathrm{~W} /(\mathrm{mK})$, while the glass granulate thermal conductivity is equal to $0.09 \mathrm{~W} /(\mathrm{mK})$. Fig. 4 shows the temperature distribution obtained from the calculation, while Fig. 5 shows the computational grid used in the computations.

In order to validate the numerical procedures, experimental verification of the computations is performed. For this purpose, the test case, being an experimental setup arrangement given in Fig. 3,

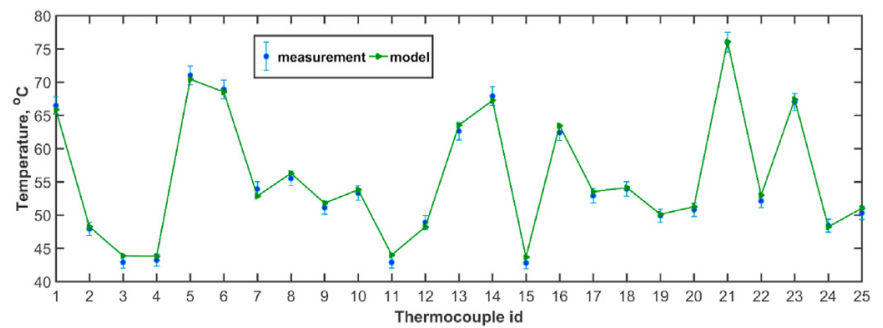

Fig. 6. Comparison between measured and calculated temperatures in points $1-25$, in reference to Fig. 3a. is considered during the computations. Fig. 6 shows the comparison between calculated temperature distribution and the temperature values measured.

The temperature distribution obtained from the developed FEM model is compared with experimental measurement results. An experimental stand (Fig. 3) is used for the ground temperature measurements in 25 locations (Fig. 3a). The FEM model of the experimental setup is developed, and temperatures within the UPCS domain are calculated. The comparison of the obtained temperature values at the location of the thermocouple is shown in Fig. 6. The comparison indicates that calculated ground temperatures do not differ more than $1^{\circ} \mathrm{C}$ from the experimental results. Therefore, the developed FEM model is used for the determination of temperature distribution in the studied UPCS.

\section{Results and discussion}

In the present study, the MJaya algorithm [3] is compared with the classical Jaya algorithm and PSO algorithms. Jaya algorithm was developed by Rao [19], and PSO algorithm was developed by Kennedy and Eberhart [23]. To compare those three algorithms operation, the quality of the Pareto front is studied by using two concepts: Coverage Concept and hypervolume (HVol) described in detail by Rao in Ref. [20]. This kind of comparison allows one to study the algorithm performance for multiobjective optimization problems.

The computations are performed by developing an in-house code in MATLAB software. Three algorithms Jaya, MJaya, and PSO, are implemented, as well as a mathematical model of heat transfer in the UPCS. The sample mesh, with results obtained for equal weights $w_{1}=0.5$ and $w_{2}=0.5$, is presented in Fig. 7 .

The following optimization results are obtained for the scaled approach for the values of weights $w_{1}$ and $w_{2}$ provided in Table 7. The values of the design variables corresponding to different weights assigned to the objective functions are also given in Table 7. The optimization results are obtained for the classical approach by using MJaya and PSO algorithms and given in Tables 8 and 9, respectively.

The results shown in Tables $7-9$ are obtained for various population sizes, i.e., $10,20,30,40$, and 50 . The maximum number of function evaluations is 1000 . The number of independent runs executed during the computation is 10 . The optimal solution depends on the values of $w_{1}$ and $w_{2}$ considered. If the UPCS designer wants to minimize the system costs (related to $F_{1}$ function), the weight $w_{1}$ should take a high value, i.e., 0.8 or 0.9 . Therefore, the effect of $F_{1}$ minimization on the objective function value $F_{o b j}$ will be significant. However, if the cable line designer wants to maximize the cable ampacity regardless of cable system costs, the $w_{2}$ should take a high value, i.e., 0.8 or 0.9 . The compromise solution uses equal weights $w_{1}=0.5$ and $w_{2}=0.5$ to obtain low costs of UPCS alongside reasonable cable line ampacity. For example for Jaya algorithm the best value of objective function for $w_{1}=0.5$ and $w_{2}=0.5$ were obtained: $F_{o b j}=0.39, F_{1}=1.7$, and $F_{2}=1.46$ what translates to cable system costs of $1.7 \mathrm{mln}$. Euro while cable ampacity is equal to $I=1460 \mathrm{~A}$.

Fig. 8 shows the Pareto front obtained for Jaya, MJaya, and PSO algorithms.

The quality of the Pareto fronts obtained by Jaya, MJaya, and PSO algorithms is compared using the Coverage concept [20]. The Coverage concept is a performance measure that compares two sets of non-dominated solutions $(A, B)$, and gives the percentage of individuals of one set dominated by the individuals of the other set. It is defined as follows: 
a)

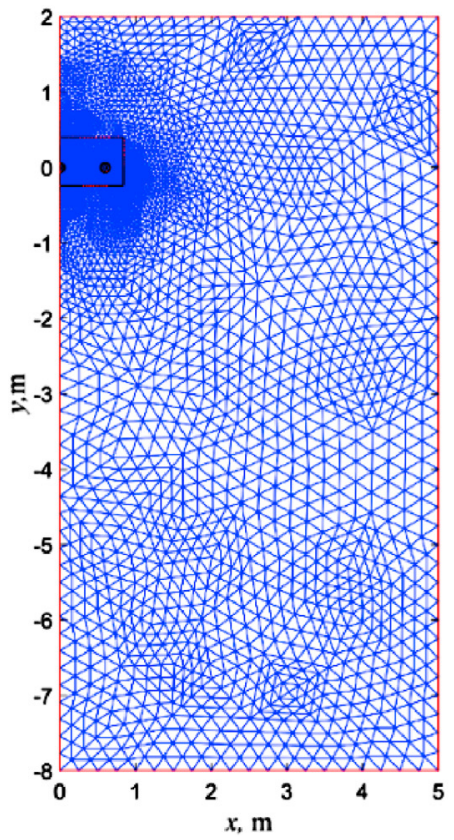

b)

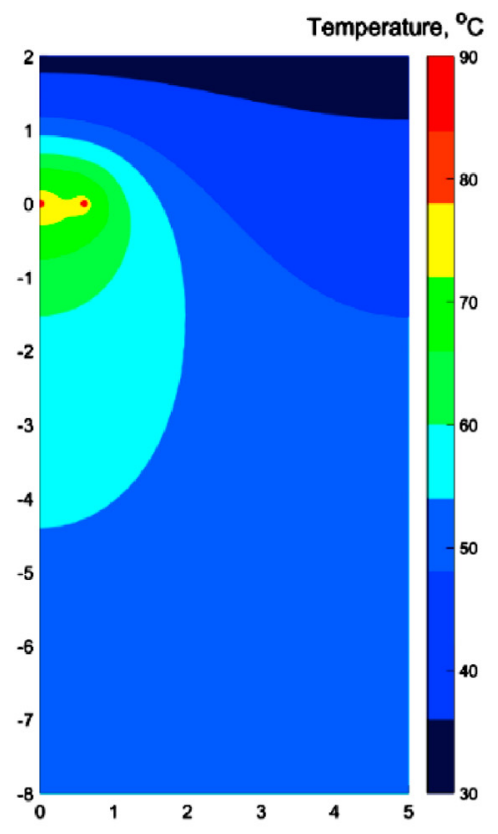

Fig. 7. The FEM model results: a) Mesh grid used in the calculation; b) temperature distribution obtained for equal weights $w_{1}=0.5$ and $w_{2}=0.5$ using MJaya algorithm.

Table 7

Optimization results obtained by using Jaya algorithm.

\begin{tabular}{|c|c|c|c|c|c|c|c|c|c|c|c|c|}
\hline \multicolumn{13}{|c|}{ Jaya algorithm } \\
\hline$w_{1}$ & $w_{2}$ & $F$ & $F_{1}$ & $F_{2}$ & $l, \mathrm{~m}$ & $p, \mathrm{~m}$ & $b, \mathrm{~m}$ & $s, m$ & $A_{c}, \mathrm{~m}^{2}$ & $10^{3} \cdot I, \mathrm{~A}$ & MAT & $T_{\max .}{ }^{\circ} \mathrm{C}$ \\
\hline 0.0 & 1.0 & 0.00 & 2.26 & 1.60 & 0.58 & 0.40 & 0.40 & 0.40 & 0.0020 & 1.600 & $\mathrm{CC}$ & 89.95 \\
\hline 0.1 & 0.9 & 0.10 & 2.23 & 1.60 & 0.60 & 0.32 & 0.40 & 0.40 & 0.0020 & 1.600 & $\mathrm{CC}$ & 90.00 \\
\hline 0.2 & 0.8 & 0.19 & 2.23 & 1.60 & 0.60 & 0.32 & 0.40 & 0.40 & 0.0020 & 1.600 & $\mathrm{CC}$ & 90.00 \\
\hline 0.3 & 0.7 & 0.29 & 2.19 & 1.59 & 0.60 & 0.25 & 0.40 & 0.40 & 0.0020 & 1.594 & $\mathrm{CC}$ & 90.00 \\
\hline 0.4 & 0.6 & 0.36 & 1.82 & 1.50 & 0.60 & 0.20 & 0.40 & 0.24 & 0.0018 & 1.504 & $\mathrm{CC}$ & 89.90 \\
\hline 0.5 & 0.5 & 0.39 & 1.70 & 1.46 & 0.60 & 0.23 & 0.40 & 0.21 & 0.0018 & 1.460 & FTB & 89.95 \\
\hline 0.6 & 0.4 & 0.39 & 1.68 & 1.45 & 0.60 & 0.20 & 0.30 & 0.28 & 0.0018 & 1.449 & FTB & 89.87 \\
\hline 0.7 & 0.3 & 0.30 & 1.29 & 1.20 & 0.60 & 0.20 & 0.24 & 0.20 & 0.0016 & 1.200 & $\mathrm{CC}$ & 89.96 \\
\hline 0.8 & 0.2 & 0.20 & 1.29 & 1.20 & 0.60 & 0.20 & 0.24 & 0.20 & 0.0014 & 1.200 & $\mathrm{CC}$ & 89.99 \\
\hline 0.9 & 0.1 & 0.10 & 1.29 & 1.20 & 0.60 & 0.20 & 0.24 & 0.20 & 0.0014 & 1.200 & $\mathrm{CC}$ & 90.00 \\
\hline 1.0 & 0.0 & 0.00 & 1.29 & 1.20 & 0.60 & 0.20 & 0.24 & 0.20 & 0.0014 & 1.200 & $\mathrm{CC}$ & 89.98 \\
\hline
\end{tabular}

Table 8

Optimization results obtained by using the modified Jaya algorithm.

\begin{tabular}{|c|c|c|c|c|c|c|c|c|c|c|c|c|}
\hline \multicolumn{13}{|c|}{ MJaya algorithm } \\
\hline$w_{1}$ & $w_{2}$ & $F$ & $F_{1}$ & $F_{2}$ & $l, \mathrm{~m}$ & $p, \mathrm{~m}$ & $b, \mathrm{~m}$ & $s, m$ & $A_{c}, \mathrm{~m}^{2}$ & $10^{3} \cdot \mathrm{I}, \mathrm{A}$ & MAT & $\overline{T_{\max } \cdot{ }^{\circ} \mathrm{C}}$ \\
\hline 0.0 & 1.0 & 0.00 & 2.24 & 1.60 & 0.60 & 0.34 & 0.40 & 0.40 & 0.002 & 1.600 & $\mathrm{CC}$ & 89.91 \\
\hline 0.1 & 0.9 & 0.10 & 2.23 & 1.60 & 0.60 & 0.32 & 0.40 & 0.40 & 0.002 & 1.600 & $\mathrm{CC}$ & 90.00 \\
\hline 0.2 & 0.8 & 0.19 & 2.23 & 1.60 & 0.60 & 0.32 & 0.40 & 0.40 & 0.002 & 1.600 & $\mathrm{CC}$ & 90.00 \\
\hline 0.3 & 0.7 & 0.29 & 2.18 & 1.59 & 0.60 & 0.23 & 0.40 & 0.40 & 0.002 & 1.594 & $\mathrm{CC}$ & 90.00 \\
\hline 0.4 & 0.6 & 0.36 & 1.86 & 1.52 & 0.60 & 0.20 & 0.40 & 0.38 & 0.0018 & 1.504 & $\mathrm{CC}$ & 89.88 \\
\hline 0.5 & 0.5 & 0.39 & 1.71 & 1.46 & 0.60 & 0.24 & 0.40 & 0.24 & 0.0018 & 1.460 & FTB & 89.97 \\
\hline 0.6 & 0.4 & 0.39 & 1.69 & 1.45 & 0.60 & 0.20 & 0.38 & 0.20 & 0.0018 & 1.449 & FTB & 90.00 \\
\hline 0.7 & 0.3 & 0.30 & 1.29 & 1.20 & 0.60 & 0.20 & 0.24 & 0.20 & 0.0016 & 1.200 & $\mathrm{CC}$ & 90.00 \\
\hline 0.8 & 0.2 & 0.20 & 1.29 & 1.20 & 0.60 & 0.20 & 0.24 & 0.20 & 0.0014 & 1.200 & $\mathrm{CC}$ & 90.00 \\
\hline 0.9 & 0.1 & 0.10 & 1.29 & 1.20 & 0.60 & 0.20 & 0.24 & 0.20 & 0.0014 & 1.200 & $\mathrm{CC}$ & 90.00 \\
\hline 1.0 & 0.0 & 0.00 & 1.29 & 1.20 & 0.60 & 0.20 & 0.24 & 0.20 & 0.0014 & 1.200 & $\mathrm{CC}$ & 90.00 \\
\hline
\end{tabular}

$\operatorname{Cov}(A, B)=\frac{|\{b \in B \mid \exists a \in A: a<=b\}|}{|B|}$

where, $A$ and $B$ are the two non-dominated sets of solutions under comparison; $a<=$ bmeans $a$ dominates $b$ or is equal to $b$.
The value $\operatorname{Cov}(A, B)=1$ means that all points in $B$ are dominated by or equal to all points in $A$ and $\operatorname{Cov}(A, B)=0$ represents the situation when none of the solutions in $B$ are covered by the set $A$. Here, it is imperative to consider both $\operatorname{Cov}(A, B)$ and $\operatorname{Cov}(B, A)$ since $\operatorname{Cov}(A, B)$ is not necessarily equal to $1-\operatorname{Cov}(B, A)$. When $\operatorname{Cov}(A, B)=1$ and $\operatorname{Cov}(B, A)=0$ then, it is said that the solutions in $A$ completely 
Table 9

Optimization results obtained by using PSO algorithm.

\begin{tabular}{|c|c|c|c|c|c|c|c|c|c|c|c|c|}
\hline \multicolumn{13}{|c|}{ PSO algorithm } \\
\hline$w_{1}$ & $w_{2}$ & $F_{o b j}$ & $F_{1}$ & $F_{2}$ & $l, \mathrm{~m}$ & $p, \mathrm{~m}$ & $b, \mathrm{~m}$ & $s, m$ & $A_{c}, \mathrm{~m}^{2}$ & $10^{3} \cdot \mathrm{I}, \mathrm{A}$ & $M A T$ & $T_{\max } \cdot{ }^{\circ} \mathrm{C}$ \\
\hline 0.0 & 1.0 & 0.00 & 2.25 & 1.60 & 0.60 & 0.40 & 0.40 & 0.37 & 0.002 & 1.600 & $\mathrm{CC}$ & 89.87 \\
\hline 0.1 & 0.9 & 0.10 & 2.23 & 1.60 & 0.60 & 0.32 & 0.40 & 0.40 & 0.002 & 1.600 & $\mathrm{CC}$ & 90.00 \\
\hline 0.2 & 0.8 & 0.19 & 2.23 & 1.60 & 0.60 & 0.32 & 0.40 & 0.40 & 0.002 & 1.600 & $\mathrm{CC}$ & 90.00 \\
\hline 0.3 & 0.7 & 0.29 & 2.23 & 1.60 & 0.60 & 0.32 & 0.40 & 0.40 & 0.002 & 1.594 & $\mathrm{CC}$ & 90.00 \\
\hline 0.4 & 0.6 & 0.37 & 1.82 & 1.50 & 0.60 & 0.23 & 0.34 & 0.28 & 0.0018 & 1.504 & $\mathrm{CC}$ & 90.00 \\
\hline 0.5 & 0.5 & 0.39 & 1.71 & 1.46 & 0.60 & 0.20 & 0.40 & 0.29 & 0.0018 & 1.460 & FTB & 89.93 \\
\hline 0.6 & 0.4 & 0.39 & 1.70 & 1.46 & 0.60 & 0.21 & 0.40 & 0.23 & 0.0018 & 1.449 & FTB & 89.84 \\
\hline 0.7 & 0.3 & 0.30 & 1.29 & 1.20 & 0.60 & 0.20 & 0.22 & 0.26 & 0.0016 & 1.200 & $\mathrm{CC}$ & 89.89 \\
\hline 0.8 & 0.2 & 0.20 & 1.29 & 1.20 & 0.60 & 0.20 & 0.20 & 0.30 & 0.0014 & 1.200 & $\mathrm{CC}$ & 89.98 \\
\hline 0.9 & 0.1 & 0.10 & 1.29 & 1.20 & 0.60 & 0.20 & 0.23 & 0.23 & 0.0014 & 1.200 & $\mathrm{CC}$ & 89.98 \\
\hline 1.0 & 0.0 & 0.00 & 1.29 & 1.20 & 0.60 & 0.30 & 0.40 & 0.40 & 0.0014 & 1.200 & $\mathrm{CC}$ & 89.97 \\
\hline
\end{tabular}

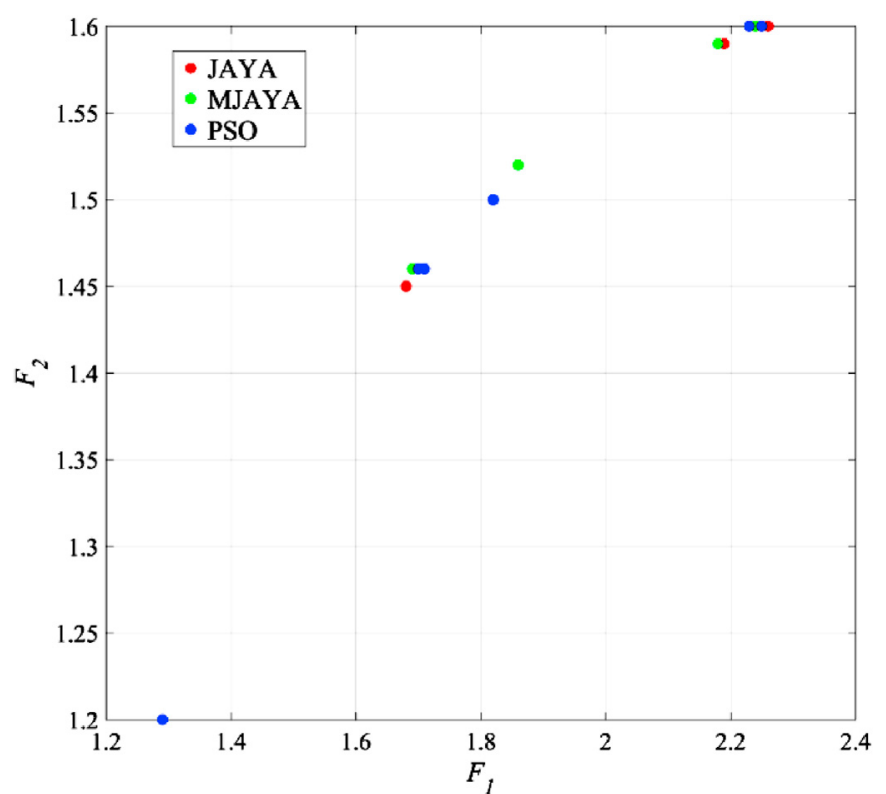

Fig. 8. Pareto fronts obtained for Jaya, MJaya, and PSO algorithms.

dominate the solutions in $B$ (i.e., this is the best possible performance of $A) \cdot \operatorname{Cov}(A, B)$ represents the percentage of solutions in set $B$, which are either inferior or equal to the solutions in set $A ; \operatorname{Cov}(B$, $A$ ) represents the percentage of solutions in set $A$, which are either inferior or equal to the solutions in set $B$.

When applying the Coverage concept, the Pareto fronts obtained by using Jaya, MJaya, and PSO algorithms are compared, and the Coverage values are given in Table 10.

A high value of Cov shows that the algorithm performs better than the other algorithms tested. The results indicated in Table 10 show that Jaya and MJaya algorithms solutions dominate 8 out of 11 PSO solutions. In the case of Jaya and MJaya algorithms, both algorithms have shown equal coverage values indicating that the Pareto fronts produced by these two algorithms are equally good.
To differentiate the Pareto fronts obtained by Jaya, MJaya, and PSO algorithms, another performance measure, known as hypervolume, is considered. The hypervolume (HVol) is used to compare the quality of Pareto-fronts obtained by optimization algorithms in the case of multiobjective optimization problems. HVol gives the search space volume, which is dominated by a Pareto-front obtained by a particular algorithm concerning a given reference point. Therefore for a particular algorithm, a higher value of HVol is desirable, which indicates the quality of the Pareto-front obtained by the algorithm [20].

Mathematically, for a Pareto-front containing $Q$ solutions, for each solution $I$ belong to $Q$ a hypervolume $v_{\mathrm{i}}$ is constructed with reference point $W$ and the solution $i$ as the diagonal corners of the hypercube. After that, the union of these hypercubes is found, and its hypervolume is calculated as follows.

HVol = volume $\left(\mathrm{U}_{\mathrm{i}=1}^{|\mathrm{Q}|} \mathrm{v}_{\mathrm{i}}\right)$

The hypervolume values are calculated for the Pareto fronts obtained by Jaya, MJaya, and PSO algorithms, taking a suitable reference point. The values are given below.

MJaya algorithm: hypervolume $=13.729$.

Jaya algorithm: hypervolume $=13.727$.

PSO algorithm: hypervolume $=13.717$.

From the above relative values of hypervolume, it can be observed that the hypervolume obtained by MJaya algorithm is slightly higher than that of Jaya and PSO algorithms. The hypervolume obtained by the Jaya algorithm is also slightly higher than that of the PSO algorithm. The difference between MJaya and Jaya algorithms performance for the studied design optimization problem of the UPCS is negligible. However, there is some improvement of MJaya and Jaya operation compared to the PSO algorithm.

\section{Conclusions}

This paper presents a multiobjective optimization of the UPCS. The goal of the paper is to minimize the UPCS materials costs (power cable costs and thermal backfill material costs) while

Table 10

Comparison of Algorithms using the Coverage Concept.

\begin{tabular}{|c|c|}
\hline \multicolumn{2}{|c|}{ Algorithm comparison - Coverage values } \\
\hline $\operatorname{Cov}($ Jaya, MJaya $)=7 / 11=0.6363$ & $\operatorname{Cov}($ MJaya, Jaya $)=7 / 11=0.6363$ \\
\hline $\operatorname{Cov}($ Jaya, $\mathrm{PSO})=8 / 11=0.7272$ & $\operatorname{Cov}(\mathrm{PSO}, \mathrm{Jaya})=1 / 11=0.0909$ \\
\hline $\operatorname{Cov}($ MJaya, PSO $)=8 / 11=0.7272$ & $\operatorname{Cov}($ PSO,MJaya $)=1 / 11=0.0909$ \\
\hline
\end{tabular}


maximizing the current flowing through the cable conductor. The two-dimensional heat transfer model is applied to calculate a temperature distribution in the UPCS. The modified Jaya algorithm is proposed as the optimization algorithm, and the algorithm's results are compared with those of the classical Jaya algorithm and PSO algorithm.

The proposed multiobjective optimization algorithm allows one to design an UPCS depending on minimizing of material cots while maximizing the current flow through the cable. Depending on the weight selection either the cost minimization or electric current flowing is prioritized. The Cable Cem backfill produced by HeidelbergCement Group seems to be a best solution for most of the analyzed cases with respect to material cost minimization and current flow maximization.

The significant difference between the modified Jaya and classical Jaya algorithm is the selection of best candidates that are used to generate the next candidate generation. The classical Jaya algorithm uses only one best solution during the iteration, while the Modified Jaya algorithm uses randomly one of the three best solutions to generate solution candidates in the following iteration. The Coverage and Hypervolume metrics are used to compare the results of the optimization obtained by Jaya, MJaya and PSO algorithms. The Coverage analysis results show that Jaya and MJaya algorithms solutions dominate 8 out of 11 PSO solutions for the considered case study. Moreover, the Hypervolume value shows better results for Jaya and MJaya in relation to PSO. Thus, it may be concluded that both the Jaya and MJaya algorithms performed better compared to the PSO algorithm. The difference in the performance of MJaya and Jaya for a studied multiobjective optimization problem of the UPCS design is slight and both of those algorithms allowed to obtain similar solutions.

\section{Credit author statement}

P. Ocłoń - writing, computation, paper concept, M. Rerak experimental validation of the mathematical model R.V Rao multiobjective optimization algorithm development P. Cisek measurement of thermal conductivity during the experimental procedure A. Vallati - support in development of mathematical model of underground power cable system D. Jakubek and B. Rozegnał - support in literature survey of the paper.

\section{Declaration of competing interest}

The authors declare that they have no known competing financial interests or personal relationships that could have appeared to influence the work reported in this paper.

\section{References}

[1] NRG Expert. Electricity T\&D white paper. www.nrgexpert.com; 2013.

[2] Metwally I, Al-Badi A, Al Farsi A. Factors influencing ampacity and temperature of underground power cables. J Inst Eng Electr Eng Div 2013;95(4): 383-92.

[3] Ocłoń P, Cisek P, Rerak M, Taler D, Rao RV, Vallati A, Pilarczyk M. Thermal performance optimization of the underground power cable system by using a modified Jaya algorithm. Int J Therm Sci 2018;123:162-80.

[4] Anders G. J, Rating of electric power Cables in unfavorable thermal environment. Wiley-IEEE Press; 2005.

[5] Moutassem W, Anders GJ. Configuration optimization of underground cables for best ampacity, Power Delivery. IEEE Transactions on 2010;25:2037-45.

[6] Ocłoń P, Bittelli M, Cisek P, Kroener E, Pilarczyk M, Taler D, Rao RV, Vallati A. The performance analysis of a new thermal backfill material for underground power cable system. Appl Therm Eng 2016;108:233-50.

[7] Ocłoń P, Cisek P, Taler D, Pilarczyk M, Szwarc T. Optimizing of the underground power cable bedding using momentum-type particle swarm optimization method. Energy 2015;92:230-9.

[8] Quan L, Fu C, Si W, Yang J, Wang Q. Numerical study of heat transfer in underground power cable system. Energy Procedia 2019;158:5317-22.

[9] Klimenta D, Tasić D, Jevtić M. The use of hydronic asphalt pavements as an alternative method of eliminating hot spots of underground power cables. Appl Therm Eng 2020;168:114818.

[10] Klimenta D, Perović B, Klimenta J, Jevtić M, Milovanović M, Krstić I. Modelling the thermal effect of solar radiation on the ampacity of a low voltage underground cable. Int J Therm Sci 2018;134:507-16.

[11] Cichy A, Sakowicz B, Kamiński M. Detailed model for calculation of life-cycle cost of cable ownership and comparison with the IEC formula. Elec Power Syst Res 2018;154:463-73.

[12] Cichy A, Sakowicz B, Kaminski M. Economic optimization of an underground power cable installation. IEEE Trans Power Deliv 2018;33(3):1124-33.

[13] Zarchi DA, Vahidi B, Haji MM. Optimal configuration of underground cables to maximise total ampacity considering current harmonics, Generation, vol. 8. Transmission \& Distribution; 2014. p. 1090-7. IET.

[14] Zarchi DA, Vahidi B. Multi objective self adaptive optimization method to maximize ampacity and minimize cost of underground cables. Journal of Computational Design and Engineering 2018;5(4):401-8.

[15] Kroener E, Vallati A, Bittelli M. Numerical simulation of coupled heat, liquid water and water vapor in soils for heat dissipation of underground electrical power cables. Appl Therm Eng 2014;70:510-23.

[16] Hruška M, Clauser C, De Doncker RW. Influence of dry ambient conditions on performance of underground medium-voltage DC cables. Appl Therm Eng 2019;149:1419-26.

[17] Rerak M, Ocłoń P. Thermal analysis of underground power cable system. J Therm Sci 2017;26(5):465-71.

[18] Ocłoń P, Cisek P, Pilarczyk M, Taler D. Numerical simulation of heat dissipation processes in underground power cable system situated in thermal backfill and buried in a multilayered soil. Energy Convers Manag 2015;95:352-70.

[19] Rao RV. Jaya: a simple and new optimization algorithm for solving constrained and unconstrained optimization problems. Int J Ind Eng Comput 2016;7:19-34.

[20] Rao RV. Jaya: an advanced optimization algorithm and its engineering applications 2019;47(5):770-80. Springer International Publishing, Cham.

[21] Thue WA. Electrical power cable engineering. third ed. CRC Press; 2011.

[22] High voltage underground power cables, Nexans company materials, available online: $60-500 \mathrm{kV}$ high voltage underground power cables XLPE insulated cables.

[23] Kennedy J, Eberhart R. Particle swarm optimization. Neural Network 1995;IV: 1942-8. 